\title{
Corrosion Behavior of Brazed Zinc-Coated Structured Sheet Metal
}

\author{
A. Nikitin, L. Schleuss, R. Ossenbrink, and V. Michailov \\ Department of Joining and Welding Technology, Brandenburg University of Technology Cottbus-Senftenberg, \\ Konrad-Wachsmann-Allee 17, 03046 Cottbus, Germany
}

Correspondence should be addressed to R. Ossenbrink; ralf.ossenbrink@b-tu.de

Received 31 August 2016; Accepted 1 December 2016; Published 15 January 2017

Academic Editor: Yu Zuo

Copyright (C) 2017 A. Nikitin et al. This is an open access article distributed under the Creative Commons Attribution License, which permits unrestricted use, distribution, and reproduction in any medium, provided the original work is properly cited.

\begin{abstract}
Arc brazing has, in comparison to arc welding, the advantage of less heat input while joining galvanized sheet metals. The evaporation of zinc is reduced in the areas adjacent to the joint and improved corrosion protection is achieved. In the automotive industry, lightweight design is a key technology against the background of the weight and environment protection. Structured sheet metals have higher stiffness compared to typical automobile sheet metals and therefore they can play an important role in lightweight structures. In the present paper, three arc brazing variants of galvanized structured sheet metals were validated in terms of the corrosion behavior. The standard gas metal arc brazing, the pulsed arc brazing, and the cold metal transfer (CMT $\left.{ }^{\circledR}\right)$ in combination with a pulsed cycle were investigated. In experimental climate change tests, the influence of the brazing processes on the corrosion behavior of galvanized structured sheet metals was investigated. After that, the corrosion behavior of brazed structured and flat sheet metals was compared. Because of the selected lap joint, the valuation of damage between sheet metals was conducted. The pulsed CMT brazing has been derived from the results as the best brazing method for the joining process of galvanized structured sheet metals.
\end{abstract}

\section{Introduction}

Galvanized sheet metals have good corrosion resistance to atmospheric corrosion and therefore they are widely used in the automotive industry [1]. However, during the arc welding of such sheet metals, the protective zinc layer is badly damaged, so that even the zinc anode protection does not prevent the atmospheric steel corrosion. The zinc coating evaporates as a result of the large heat input of arc welding processes. Furthermore, zinc vapor and zinc oxides lead to pores in the weld metal and an unstable arc behavior [2]. These problems are reduced by bonding or brazing. During bonding, there is no or less heat input and thus the protective zinc layer remains intact. However, often the strength of the adhesive bond is insufficient [3]. The arc brazing advantage is the higher joint strength, which can reach the strength of the base material, and significantly reduced heat input compared to the arc welding. The disadvantages of welding and bonding are simultaneously solved [4]. The technology of cold metal transfer (CMT) is a further development of arc welding and brazing processes, which even more reduces the heat input into the joined components $[5,6]$.

The lightweight design plays a key role in the automotive industry to achieve climate targets and to reduce energy consumption. Structuring of sheet metals increases their stiffness and reduces their weight. After the structuring process by hydroforming, the corrosion resistance of zinccoated sheet metals slightly increased, which was studied in [7]. Galvanized structured sheet metals could be applied in various fields such as automotive and construction industry [8] which also reflects the application fields of the arc brazing. Structured sheet metals were already qualified for further processing, especially in the field of metal forming $[9,10]$, cutting $[11,12]$, and welding [13-17]. Their mechanical properties were studied in $[18,19]$. The corrosion behavior of galvanized structured sheet metals was studied in nonwelded joints in [7, 20]. Consequently, there is a need to validate the brazed joints corrosion behavior of galvanized structured sheet metals. 
TABLE 1: Geometrical characteristics of the structured sheet metals.

\begin{tabular}{lccc}
\hline \multicolumn{4}{c}{ Geometrical characteristics [mm] } \\
\hline SW & SL & SH & BW \\
33 & 36 & 3.1 & 2 \\
\hline
\end{tabular}

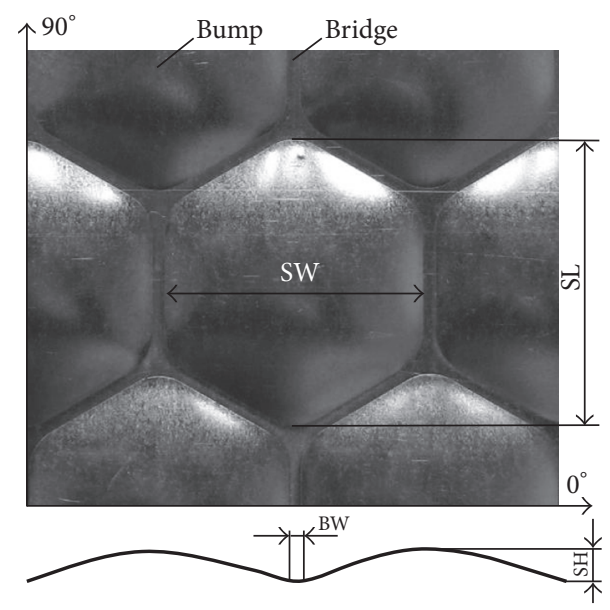

FIGURE 1: Zink-coated structured sheet metal with structure directions 0 and $90^{\circ}$.

\section{Experimental Details}

2.1. Structured Sheet Metals. Structured sheet metals have a hexagonal structure. The production method is hydroforming [10]. The sheet metals consist of stiffening elements with hexagonal bumps, whose dimensions are shown in Figure 1 and described in Table 1 with specific values.

Due to the asymmetry relating to the sheet plain, there are two structural locations: the structure location is "positive" if the curvature extends upwards and "negative" if the curvature extends inwards. In [20], a small difference of the corrosion behavior between the structure locations is described. All specimens were brazed in the positive structure location and in the structure direction $0^{\circ}$. Therefore, a top and a bottom side of brazed samples, respectively, coincide with the positive and negative structure location of the structured sheet metal.

In the present paper, the atmospheric corrosion of the protective coat damaging by galvanized sheets brazing was studied. The estimated locations for corrosion of the brazed joint are shown in Figure 2. Areas 1 and 2 are located beside the brazed joint on the top side of the joint. Area 3 is on the seam bottom side. Because of the probable zinc layer damage, these three areas are most susceptible against corrosion due to the brazing process heat input. At area 4 , the risk of corrosion is high, not only due to protective layer destruction, but also because of the gap existence by overlapping where corrosive media can be accumulated and the corrosion processes accelerated.

For corrosion tests, thin sheet metals were used. The steel type is DX56D $+\mathrm{Z}$. This is hot-dip galvanized low carbon steel with $10 \mu \mathrm{m}$ coating thickness. The sheet thickness was $0.5 \mathrm{~mm}$.

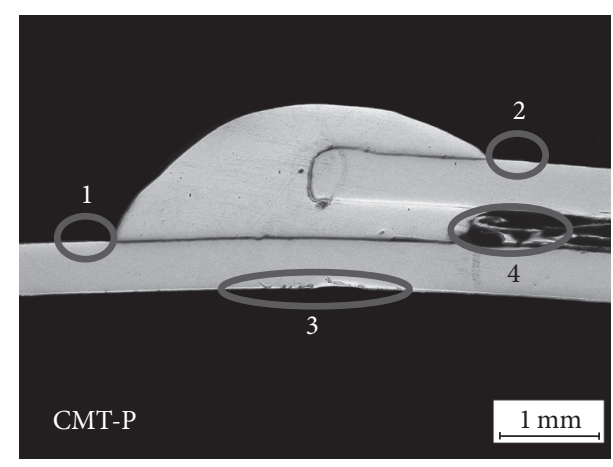

FiguRE 2: The probable locations of the corrosion occurrence.

2.2. Brazing Process. Mechanized brazing was carried out by robot system Kuka 30 HA (high accuracy). First, brazing tests were conducted on the flat sheet metals of similar thickness and similar material to determine the initial parameters. It turned out that the flat sheet metals could be qualitatively brazed without special requirements by linear torch controlling normal to the sheet plain. When transferring these parameters on structured sheet metals, the threedimensional structure caused a continuous variation of the brazing conditions, especially on the contact tube spacing and the incidence angle between the brazing torch and the plate. The brazing with the same parameters showed bad quality of the brazed joints. The contact tube spacing (the distance between torch and sheet) has a significant influence on the brazed joint quality. These effects are described for the GMA welding in [13]. In [11], it was reported that an altitude correction in dependence on the arc voltage at the plasma cutting of the structured sheet metals has a positive effect on the cutting quality. However, since a height correction at the pulse arcs cannot be used as a control variable, the structure height values were measured along the brazing zone and transferred to the robot program. Consequently, the robot path has been realized with a constant distance between the torch and the sheet metal.

The gas metal arc (GMA) brazing of the structured sheet metals was investigated by three different processes variants [21]. The parameters for the standard gas metal arc brazing (hereinafter GMAB), the pulsed arc brazing (hereinafter GMAB-P), and the cold metal transfer (CMT) in combination with a pulsed cycle (hereinafter CMT-P) were determined. The standard GMAB involves the conventional arc brazing with drop transfer at the short circuit. The main disadvantages of this method due to the short circuit are increasing energy consumption and spattering. The pulsed arc brazing leads to a drop transfer which is almost free from the short circuit and free of spattering. The third examined process variant CMT brazing is based on a reversing wire supply, which moves the brazing wire with a frequency up to $90 \mathrm{~Hz}$ back and forward. At first, the arc ignites at the wire tip. Then, the forward movement of the wire begins at the same time with drop formation at the wire tip. By the contact due to the forward movement of the wire, the drop at the wire tip is transferred to the sheet and the arc is extinguished, 
TABLE 2: Process parameters for GMA brazing of the structured and flat sheet metal.

(a) Brazing parameters for the structured sheet metals

\begin{tabular}{lccc}
\hline Brazing method & GMAB & GMAB-P & CMT-P \\
\hline Current [A] & 74 & 39 & 37 \\
Voltage [V] & 13.5 & 16.5 & 13.6 \\
Wire speed [m/min] & 3.5 & 2.2 & 2.3 \\
\hline
\end{tabular}

(b) Brazing parameters for the flat sheet metals

\begin{tabular}{lccc}
\hline Brazing method & GMAB & GMAB-P & CMT-P \\
\hline Current [A] & 82 & 54 & 40 \\
Voltage [V] & 13.5 & 17.9 & 13.6 \\
Wire speed [m/min] & 4.1 & 2.8 & 2.5 \\
\hline
\end{tabular}

TABle 3: Physical properties of the filler material [21].

\begin{tabular}{lcccc}
\hline $\begin{array}{l}\text { Filler } \\
\text { material }\end{array}$ & $\begin{array}{c}\text { Melting } \\
\text { point }\left[{ }^{\circ} \mathrm{C}\right]\end{array}$ & $\begin{array}{c}\text { Tensile } \\
\text { strength }[\mathrm{MPa}]\end{array}$ & $\begin{array}{c}\text { Elongation } \\
{[\%]}\end{array}$ & $\begin{array}{c}\text { Hardness } \\
{[\mathrm{HB}]}\end{array}$ \\
\hline CuSi3 & $910-1026$ & $330-370$ & 40 & $80-90$ \\
\hline
\end{tabular}

so that the metal transfer almost without current occurs. Subsequently, the wire is pulled back after the extinction of the arc. The described variant of CMT brazing was improved by the pulse technique, so that during the drop formation more filler material is melted by the increased current pulse.

In Table 2, the brazing parameters for flat and structured sheet metals are presented. For gas metal arc brazing, a filler material $\mathrm{CuSi} 3$ with diameter $1.0 \mathrm{~mm}$ was used. Table 3 shows the relevant physical properties of the filler material. Due to the low melting temperature, this filler wire is used very often for the GMA brazing of electrolytic or hot-dip galvanized sheet metals.

2.3. Corrosion Testing. Corrosion tests were carried out by applying a salt spray chamber with 1000 -liter volume; the model CT 1000-S MF was made by VLM GmbH. In this work, the climate change test according to VDA 621-415 specification [22] was selected as accelerated corrosion test. The test cycle consists of 1 day of salt spray exposure according to [23], 4 days of condensation cyclic climate according to [24], and 2 days of ambient climate. The duration of one cycle was one week. The number of cycles depends on the corrosion resistance of the specimen coatings and was 5 weeks. The results of this test are used for comparison of the corrosion resistance of various protective coatings. The corrosive medium was a $5 \mathrm{wt} . \%$ aqueous sodium chloride solution with $\mathrm{pH}$ of 6.7 . The solution temperature was $25^{\circ} \mathrm{C}$. This is necessary to ensure the independence of the results from the chamber and the comparability with the results of other studies.

Because of the lap joint, the arrangement of the specimen in the specimen holder must be considered. In Figure 3, the arrangements are shown. For the all-round analysis, it is necessary to carry out the corrosion tests for all 6 arrangement variants. To reduce the experimental scope, the corrosion tests were conducted for one arrangement of the
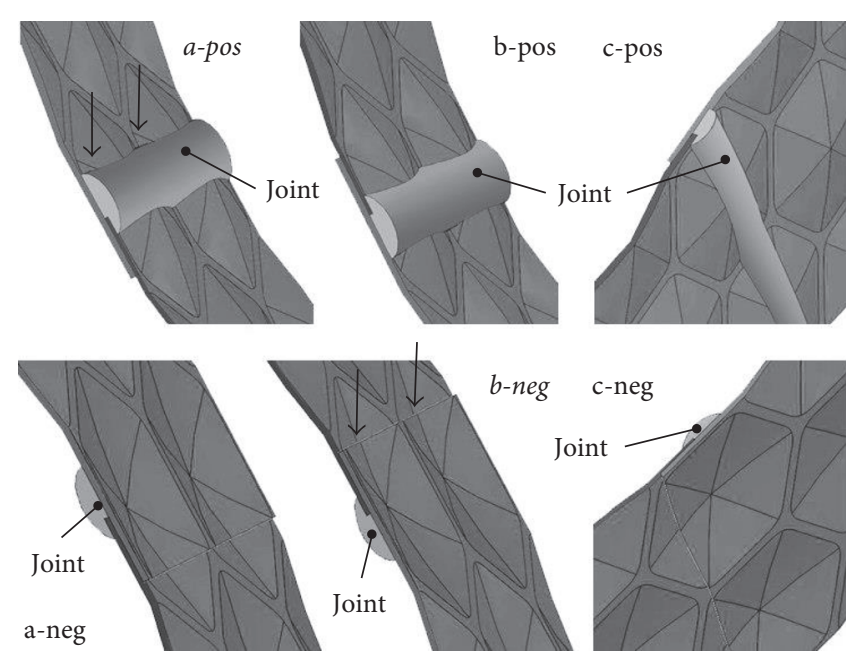

Figure 3: Variants of the arrangement of the specimen.

samples in positive and negative structure locations with the brazing seam on the top and bottom side, respectively. The reason of selecting this sample arrangement consists in the assertion that every bump plays a barrier role which accumulates the moisture and therefore provides additional conditions for corrosion [20]. According to the standard [23], the specimens must be placed at $(20 \pm 5)^{\circ}$ angle to the vertical position. The moisture and corrosion products flow down at such angle along the sample surface. In the arrangement of the a-pos brazed joint is a bigger barrier for that than the bpos. By the use of the arrangement of c-pos the brazed joint does not build a barrier for the corrosive medium. This means that the arrangement of a-pos leads to the strongest corrosion conditions. For the bottom side of the specimen, the situation is reversed. There is no brazed joint and only the edge of the second sheet in the arrangement b-neg is considered as a barrier to the salt solution. In addition, this position gives higher corrosion load for gaps between sheet metals. In an ongoing research, only variants of the specimen arrangement with bigger relief were selected for experiments: variant a-pos for the top seam side and variant b-neg for the bottom seam side.

For a conclusive analysis, it is necessary to investigate at least 3 samples for every brazing variant. Besides the structured samples, the smooth samples as a reference were brazed and investigated by the climate change test. As Table 4 shows, a total of 36 samples were tested.

The geometric specimen parameters were $150 \times 70 \mathrm{~mm}$. The examination of corroded specimens was carried out weekly. Pictures of the samples were taken. The corrosion products were not removed during the test; otherwise, the natural corrosion process would be interrupted and therefore only a visual inspection was used as an evaluation method. To increase the capacity of the evaluation, a graphical analysis of the corroded areas by using the program Leica Application Suite (LAS) Phase Expert was conducted. The program identifies the corrosion areas as percentage of the evaluation area (Figures 4 and 5) by regions of homogeneous color. 
TABLE 4: Number of specimens.

\begin{tabular}{|c|c|c|c|c|}
\hline \multirow{6}{*}{ Brazing methods } & \multicolumn{4}{|c|}{ Type of the sheet metal } \\
\hline & \multicolumn{2}{|c|}{ Flat } & \multicolumn{2}{|c|}{ Structured } \\
\hline & \multicolumn{4}{|c|}{ Sheet thickness } \\
\hline & \multirow{2}{*}{\multicolumn{2}{|c|}{$0.5 \mathrm{~mm}$}} & \multirow{2}{*}{\multicolumn{2}{|c|}{$\begin{array}{l}\text { Bump: } 0.48 \mathrm{~mm} \\
\text { Bridge: } 0.49 \mathrm{~mm}\end{array}$}} \\
\hline & & & & \\
\hline & Positive & Negative & Positive & Negative \\
\hline GMAB & 3 & 3 & 3 & 3 \\
\hline GMAB-P & 3 & 3 & 3 & 3 \\
\hline CMT-P & 3 & 3 & 3 & 3 \\
\hline \multirow{2}{*}{ Sum } & \multicolumn{2}{|c|}{18} & \multirow{2}{*}{\multicolumn{2}{|c|}{18}} \\
\hline & \multicolumn{2}{|c|}{36} & & \\
\hline
\end{tabular}

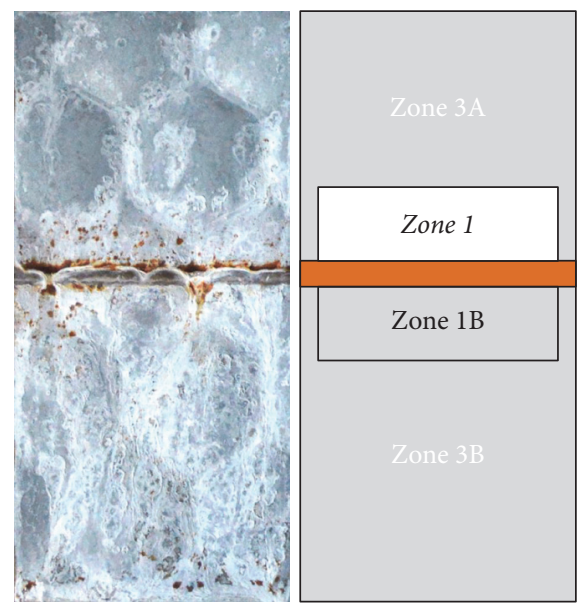

FIGURE 4: Picture of the structured specimen (top seam side) after the first week of the climate change test and scheme of the evaluation areas.

Primarily, the thresholds for homogeneous colors of "red" rust could be clearly defined.

2.4. Evaluation Method. For examination, the areas near the brazed joint were used (zone 1), because the $\mathrm{CuSi} 3$ seam is not corroded. These zones included the full width of a sample excluding the edges. The height of the zone was set at the level that was determined for all samples as detected maximum damage range, so that all corroded areas were in this zone. Zone $1 \mathrm{~B}$ under the joint was not used because it showed a consistent picture for all structured samples. The surface without zinc in this zone is corroded slower than in zone 1 . This may be explained by the fact of decreasing of moisture level due to the brazed seam, which acts as a barrier. Frequently, the accumulated water in zone 1 flows across the seam and then some spots of "red" corrosion appear in zone $1 \mathrm{~B}$ (Figure 4). Therefore, this area cannot be used for comparison. Zone 3 has no heat influence due to the brazing process and that is why there are no "red" rust areas after the first test week.

The negative structure location has no barrier seam of moisture and corrosion products. However, there is another barrier that is smaller and farther from the place where a

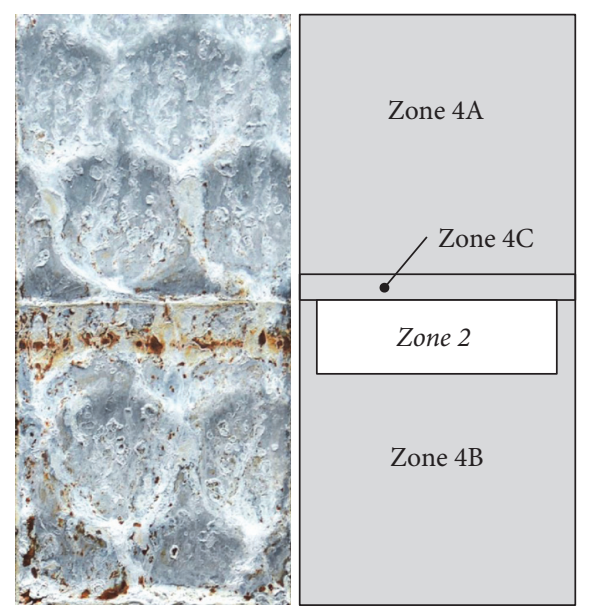

FIGURE 5: Picture of the structured specimen (bottom seam side) after the first week of the climate change test and scheme of the evaluation areas.

heat source was. This is the edge of the bottom sheet in the lap joint where the moisture is accumulated (zone 4C). However, there is no zinc coating damage due to the heat input; therefore, this zone is not important for the brazed joint corrosion investigation. Zone 2 is located directly below the brazed seam. Its borders were found by determining the maximum damaged surface.

All samples were cut before by laser beam. However, this leads to a low heat input into the edges of the samples. Therefore, side areas in $5 \mathrm{~mm}$ from the edge were not used in the examination. All sheets had comparable surfaces. Examination area was $750 \mathrm{~mm}^{2}$ for every specimen.

During the corrosion test, two types of corrosion products arise on the surface of the galvanized sheet metals. The first form is "white" rust, generally consisting of zinc oxide, zinc hydroxide, and zinc carbonate products. These products are produced by oxidation of the zinc coating in the chlorine-containing conditions. This process leads to the destruction of the protective zinc layer and steel begins to corrode. The result is the oxidation of the iron and the formation of brownish iron(II) and iron(III) oxides, or socalled "red" rust. The "white" rust has no influence on the mechanical properties of components and just changes the surface appearance. The program software for color detection was used for the examination of corrosion-damaged surface. The surface analysis was done by the evaluation of the "red" rust, because the area of "white" rust provides no clear statements on the corrosion of the brazed joint. The "white" rust is also an indication for the corrosion-damaged surface. Some "red" rust may develop under the "white" rust and cannot be detected by the program software.

Previous investigations [7] on zinc-coated structured sheet metals of the same type and material showed that "red" rust in magnitude of $22-26 \%$ develops under the "white" rust for short exposure times $(240 \mathrm{~h})$ and rapidly decreases to magnitude of $3-9 \%$ for longer exposure times. There are no significant differences between flat and structured sheet 


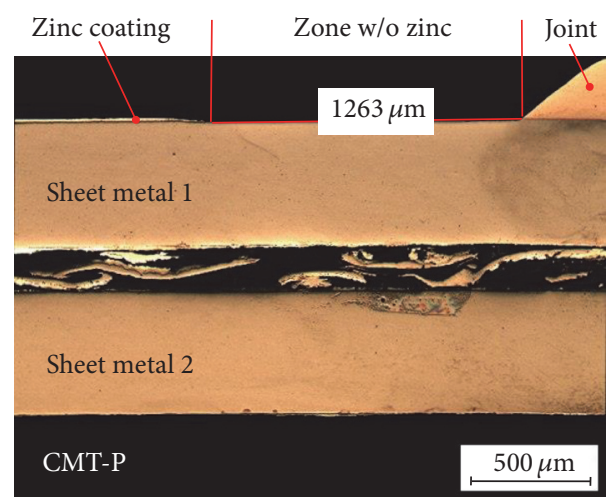

FIGURE 6: Minimum zone without zinc coating near the brazed joint.

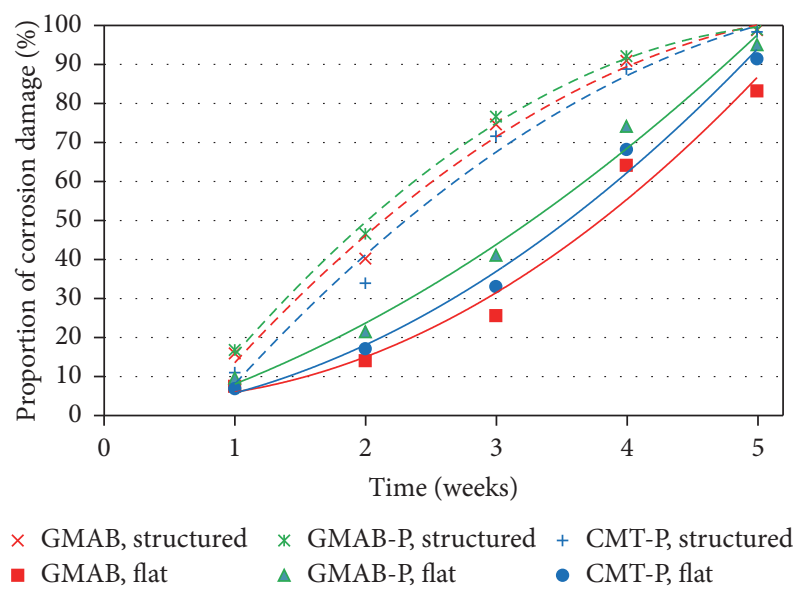

Figure 7: Results of corrosion test for zone 1 (top seam side).

metals. Transferring these results to this investigation, the relative positions and distances for the corrosion development of different brazing procedures remain unchanged and can be compared to each other.

\section{Results and Discussion}

After the brazing process, all samples had areas without zinc coating near the brazed seam. The metallographic studies confirm this fact (Figure 6). The width of this area has a direct influence on the corrosion resistance of the compound. However, due to the uneven evaporation of the zinc layer, the width of the area could not be determined exactly and the "red" rust area after the corrosion test was evaluated.

The test results were shown in Figure 7. As the curves for each brazing method are practically similar (the average deviation is less than $5 \%$ ), only the main values were used in the further comparisons for the examination. The results are converted into trend lines by approximation.

The diagram shows the increasing corrosion damage proportion in zone 1 during a period of 5 weeks. This zone 1 is located near the seam. First, the big difference between structured and flat samples is observed. In zone 1, there are more "red" corrosion products on the structured specimens

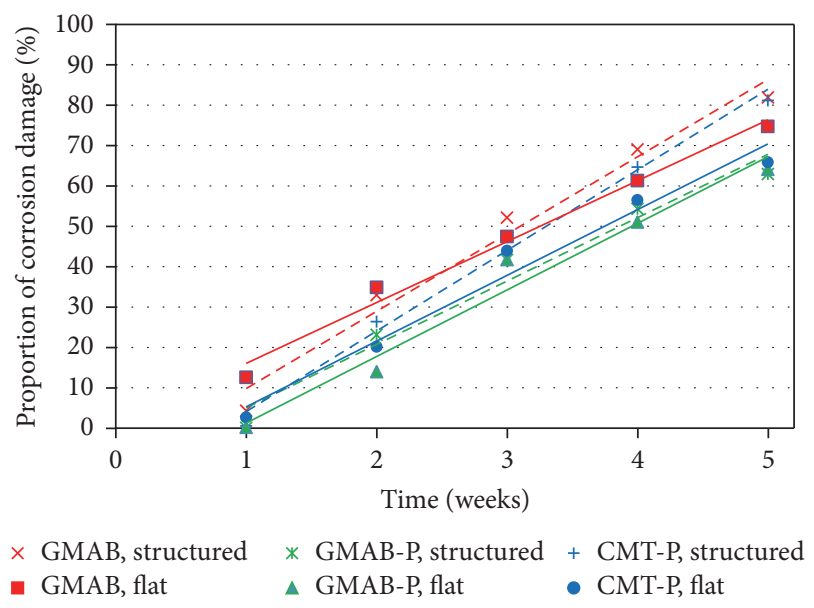

FIGURE 8: Results of the corrosion test for zone 2 (bottom seam side).

than on the flat ones. As a result, this leads to the deterioration of the compound corrosion behavior. According to [20], the corrosion products on the nonjoined flat sheet metals appear faster than on the nonbrazed structured sheet metals. This behavior seems to change, if the structured sheet metals were brazed. The brazing has a great influence on the structured sheet corrosion behavior near the compound. This can be explained by unstable brazing even when the threedimensional sheets topology is considered by the program of the used robot system for brazing. These paths take into account the changing distance from the torch to the sheet plain. Furthermore, bumps have an influence on the inert gas flow and generate the variation between rising and falling brazing positions [13]. This affects the quality of the brazed joint.

After the first week, all samples already had the "red" corrosion products near the seam. This means that the cathodic protection of the zinc coating is no longer effective. After the fifth test week, all samples in zone 1 were practically completely covered with "red" rust.

As Figure 7 shows, there is no big difference between the corrosion behaviors of the brazed joints produced by various brazing methods. This is valid for the flat sheet metals (maximum difference is $15.5 \%$ by $4.7 \%$ deviation) as well as for the structured sheet metals (maximum difference is $12.7 \%$ by $6.2 \%$ deviation). However, the pulse brazed samples show the worst results, regardless of the sheet structure. The CMT pulse brazing shows the best results for structured sheet metals. For the flat reference samples, the standard GMA brazing is the most suitable method.

The results of the corrosion test for zone 2 are shown in Figure 8 . The results of structured and flat samples showed practically no difference. Figure 8 clearly shows a major trend for the bottom seam side of the compound. The standard GMA brazing with the largest current values leads to greater heat input. Therefore, the samples prepared by the standard GMA brazing show the worst corrosion resistance on the bottom seam side. This is valid for all samples irrespective of their structure. On average, the corrosion resistance of the standard-brazed compounds is up to $12 \%$ 


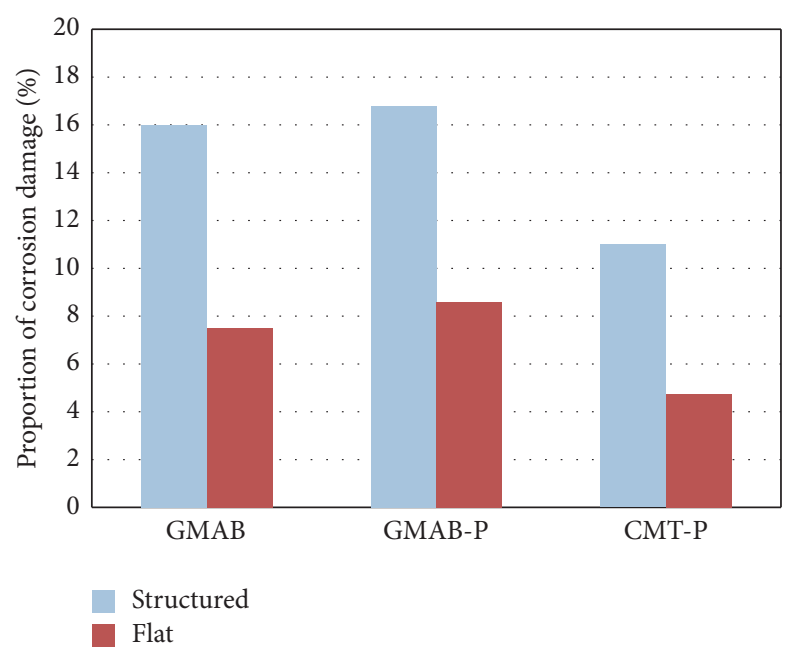

FIGURE 9: Results of the corrosion test after the first week for zone 1 (top seam side).

lower for flat samples and up to $11.6 \%$ lower for structured samples compared to the best results for flat and structured samples brazed by pulsed GMAB. The pulsed GMA brazing modification through CMT technology demonstrates worse corrosion behavior of all samples.

Zone 2 is corroded less than zone 1 , because on the bottom compound side the zinc layer was affected only by a low heat input. It was found that after the first test week a big amount of "red" rust on the bottom compound side has developed only on the standard-brazed samples.

The requirements for brazed compounds in industry consist in obtaining compound corrosion resistance comparable to the corrosion resistance of the base material. This could not be accurately detected by the corrosion test according to VDA 621-415 because the conditions of this test are very harsh. After the second week of the climate change test, the "red" rust appears on the sheet surface without thermal influence. Near the brazed seam, the spots of the "red" rust are already observed after the first test week. This means that the results after the first week are the most interesting from the brazing methods comparison point of view.

Figure 9 shows results of corrosion test for positive structure location arranged samples after the first week. It is clear that there is almost no difference in the results of the samples "GMAB" and "GMAB-P" regardless of the sheet topology. It is important to underline that the results of CMT-P samples are much better for both structured and flat samples. It should be mentioned that after the first week of the corrosion test the proportion of the corrosion damage for structured samples in zone 1 is almost two times higher than for flat samples.

The results of the corrosion test for zone 2 on the bottom seam side, which are shown in Figure 10, allow the comparison of the samples "GMAB-P" and "CMT-P." Both methods show similar low corrosion damage values of the brazed structured samples. For the flat specimens, the corrosion damage is a little higher. Zone 2 , in contrast to zone

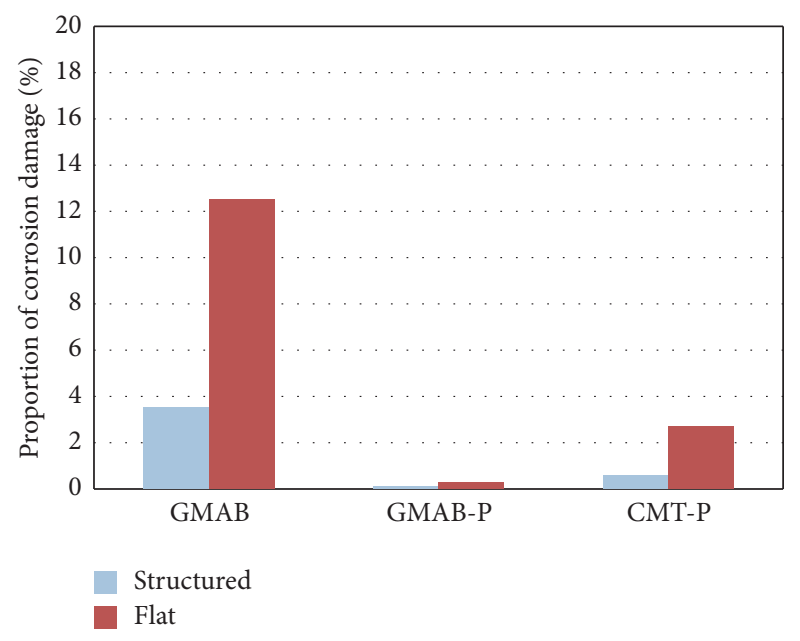

FIGURE 10: Results of the corrosion test after the first week for zone 2 (bottom seam side).

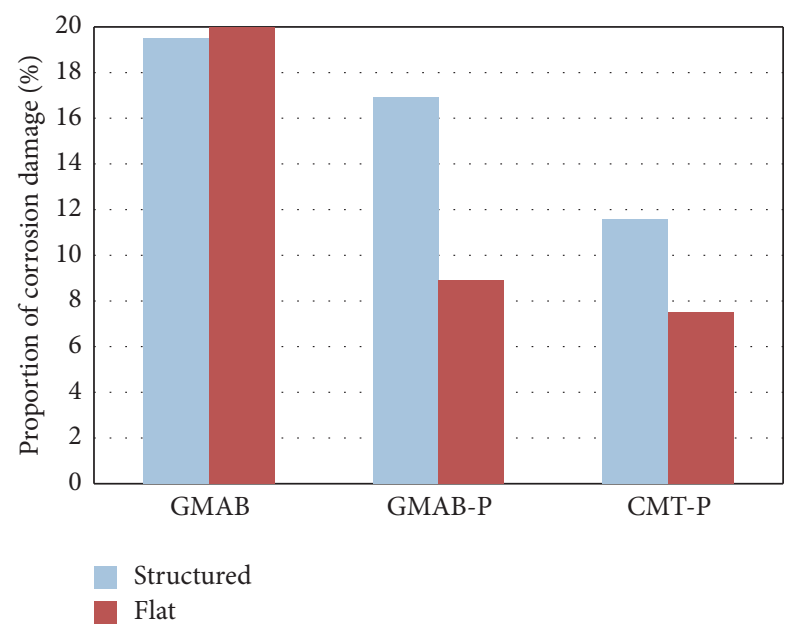

FIGURE 11: Totalized results of the corrosion test after the first week for zones 1 and 2 .

1 , demonstrates a radically different correlation between flat and structured specimens.

To make a better evaluation of these conflicting results, the data were summarized for both zones (Figure 11). This diagram shows that the standard GMA brazing leads to the worst corrosion resistance of the brazed compound compared to the pulsed GMA and pulsed CMT brazing.

There is almost no difference between the GMAB-P and CMT-P brazing of flat sheet metals from the compound corrosion behavior point of view. For structured sheet metals, the CMT-P is the best brazing method according to the climate change test.

The lap joint has a special disadvantage. At the lap joint, a gap between the joined sheets forms, so that corrosive fluids can flow into the gap. This can cause corrosion in that place. The arrangement of the specimen with negative structure let the moisture leak, so that the corrosion medium could flow into the gap. That is why visual inspection of corrosion in the overlap interior has been done for every brazing variant after 


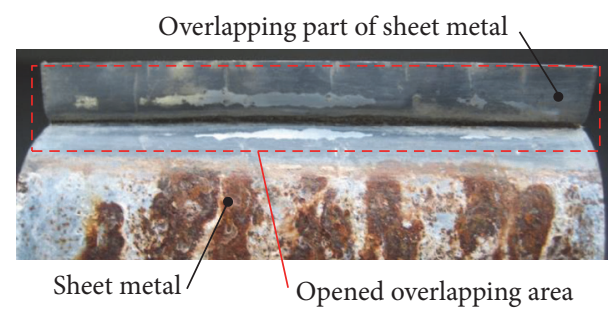

Figure 12: Picture of the gap surface in the lap joint of the GMAB brazed flat sheet metal after 5 weeks of the corrosion test.

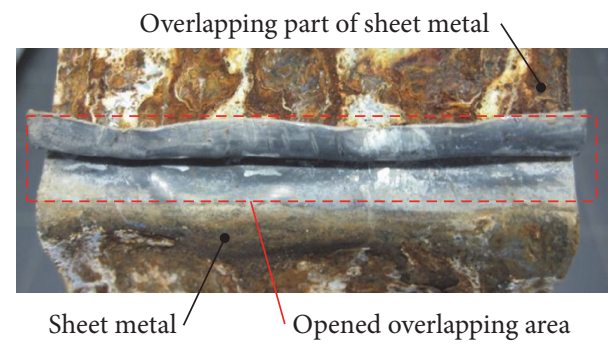

Figure 13: Picture of the gap surface in the lap joint of the GMAB-P brazed structured sheet metal after 5 weeks of the corrosion test.

5 weeks of the climate change test. For this purpose, the gap area has been opened manually by bending the overlapping part of the sheet metal.

First, the flat samples were reviewed. Figure 12 shows an example of the zinc coating condition between flat sheets after 5 weeks of the corrosion test. The "red" corrosion was not presented there. The undamaged zinc layer was retained in place. All flat samples had the same look.

For structured samples, no "red" rust was also found in the overlaps irrespective of the brazing methods (Figure 13). The main conclusion is the fact that atmospheric corrosion has no critical influence on the lap joint of galvanized sheet metals regardless of the plate topology and the brazing method.

\section{Conclusions}

The corrosion brazed joint behavior of galvanized structured sheet metals is affected by the brazing parameters. However, the greatest difference of the corrosion behavior was seen in the results for structured and flat sheet metals on the top side of the joint: the structured sheet metals are corroded much stronger than joints of the flat sheet metals. On the bottom side of the brazed compounds, the situation is quite the opposite. In general, the corrosion damage on the negative side of the brazed joint was significantly lower than on the top side (with the exception of flat samples "GMAB").

The process of conventional GMA brazing is characterized by a bigger heat input in comparison to the pulsed GMA brazing and the pulsed CMT process. Therefore, the specimens of the standard brazing process have reduced corrosion resistance.

The brazed top compound side shows the worst corrosion behavior by using pulsed GMA brazing method. The opposite was true for the bottom side: the corrosion behavior was the best. Therefore, this brazing method is better in comparison with the standard brazing process.

The pulsed CMT brazing showed on the both top and bottom sides almost the best results. This method can be recommended as the preferred brazing variant for the joining of galvanized flat and structured sheet metals.

Regardless of the brazing process, the corrosion between the overlapping galvanized sheet metals is not critical. This can be explained by the fact that the corrosive medium does not flow into the gap. And that is why there is no big load on the zinc coating.

By using the bottom seam side of the sheet metal as a functional surface, the best way of arc brazing is pulsed GMA brazing. In all other cases, the pulsed CMT brazing is the best brazing process to join the galvanized structured sheet metals.

\section{Competing Interests}

The authors declare that they have no competing interests.

\section{Acknowledgments}

This work was supported by the Brandenburg Ministry of Science, Research and Culture (MWFK) as part of the International Graduate School at Brandenburg University of Technology (BTU) Cottbus-Senftenberg.

\section{References}

[1] P. Maass and P. Peissker, Handbuch Feuerverzinken, Wiley, Hoboken, NJ, USA, 2012.

[2] T. Shinoda, Y. Takeuchi, and T. Shimizu, "Effect of surface active element on porosity formation by GMA welding of zn plated steel for automobile industry," in Exploiting Advances in Arc Welding Technology, pp. 63-74, Woodhead Publishing, 1999.

[3] K. Graf, L. Schleuß, R. Ossenbrink, and V. Michailov, "Auswirkungen von strukturierten Fügepartnern auf geklebte Verbindungen," in DVS-Berichte, Band 275, pp. 472-477, DVS Media GmbH, Düsseldorf, Germany, 2011.

[4] R. Killing, "MIG brazing on thin sheet metals", in Metallbau Heft 9/1999, pp. 52-54, Callwey, Munich, Germany, 1999.

[5] P. Kah, R. Suoranta, and J. Martikainen, "Advanced gas metal arc welding processes," International Journal of Advanced Manufacturing Technology, vol. 67, no. 1-4, pp. 655-674, 2013.

[6] G. Trommer, "Cold Metal Transfer and pulsed arc welding processes separately used or in combination, in order to obtain an wide power range," Sudura, vol. 20, no. 1, pp. 25-29, 2010.

[7] E. Kornienko, R. Ossenbrink, and V. Michailov, "Corrosion resistance of zinc-coated structured sheet metals," Corrosion Science, vol. 69, pp. 270-280, 2013.

[8] A. Sterzing, Bewertung von Leichtbaupotenzial und Einsatzfähigkeit wölbstrukturierter Feinbleche [Ph.D. thesis], Chemnitz University of Technology, 2005.

[9] M. Hoppe, Umformverhalten strukturierter Feinbleche [Ph.D. thesis], Brandenburg University of Technology (BTU) Cottbus, Senftenberg, Germany, 2002.

[10] V. Malikov, R. Ossenbrink, B. Viehweger, and V. Michailov, "Analytical and numerical calculation of the force and power 
requirements for air bending of structured sheet metals," Key Engineering Materials, vol. 473, pp. 602-609, 2011.

[11] L. Schleuß, Th. Richter, R. Ossenbrink, and V. Michailov, "Plasma cutting of structured sheet metals in comparison with laser beam cutting," Journal of Materials Science and Engineering $B$, vol. 5, no. 3-4, pp. 135-144, 2015.

[12] I. Sasse, L. Schleuß, R. Ossenbrink, and V. Michailov, "Cutting of structured sheet metals with high power fiber laser," in Proceedings of the International Conference on Innovative Technologies (IN-TECH '11), pp. 485-488, 2011.

[13] L. Schleuß, K. Springer, J. Zoeke, R. Ossenbrink, and V. Michailov, "Qualifizierung von wärmearmen MSG-Schweißverfahren für Leichtbaukonstruktionen aus strukturierten Halbzeugen," in JOIN-EX 2012: Internationaler Fachkongress der Schweiss-und Verbindungstechnik, 2012.

[14] I. Sasse, L. Schleuß, R. Ossenbrink, and V. Michailov, "Joining of structured sheet metals-remote laser beam welding in comparison with resistance spot welding," Welding and Cutting, vol. 13, no. 1, pp. 43-47, 2014.

[15] L. Schleuß, R. Ossenbrink, and V. Michailov, "Widerstandspunktschweißen strukturierter bleche-schweißbereiche, prüfung, anwendung," in 12. Kolloquium Widerstandsschweißen und Alternative Verfahren, Halle (Saale), pp. 54-59, 2010.

[16] I. Sasse, L. Schleuß, R. Ossenbrink, and V. Michailov, "Fügen strukturierter Bleche-Remote-Laserstrahlschweißen im Vergleich zum Widerstandspunktschweißen," in DVS-Berichte, Band 296, pp. 98-103, DVS Media, Düsseldorf, Germany, 2013.

[17] L. Schleuß, A. Brobeck, R. Ossenbrink, R. Polzin, and V. Michailov, Rollennahtschweißen Strukturierter Feinbleche, Abschlussbericht. Leibniz Information Centre for Science and Technology (TIB), Hanover, Germany, 2015.

[18] S. Fritzsche, R. Ossenbrink, and V. Michailov, "Experimental characterisation of structured sheet metal," Key Engineering Materials, vol. 473, pp. 404-411, 2011.

[19] F. Kazak, L. Schleuß, R. Ossenbrink, V. Michailov, and S. Weiß, "Particularities of testing structured sheet metals in 3-point bending tests," Materials Testing, vol. 58, no. 6, pp. 495-500, 2016.

[20] E. Kornienko, Korrosionsverhalten von strukturierten Blechen [Ph.D. thesis], Brandenburg University of Technology (BTU) Cottbus-Senftenberg, Senftenberg, Germany, 2014.

[21] A. Kliche, MIG-Löten von strukturierten Blechen [Ph.D. thesis], Brandenburg University of Technology (BTU) CottbusSenftenberg, Senftenberg, Germany, 2013.

[22] VDA-Prüfblatt 621-415: Anstrichtechnische Prüfungen, Prüfung des Korrosionsschutzes von Kraftfahrzeug-lackierungen bei zyklisch wechselnder Beanspruchung, 1982.

[23] ISO, "Corrosion tests in artificial atmospheres—salt spray tests," EN ISO 9227, 2006.

[24] "Paints and varnishes-determination of resistance to humiditypart 2: procedure for exposing test specimens in condensationwater atmospheres, 2005," EN ISO 6270-2, 2005. 

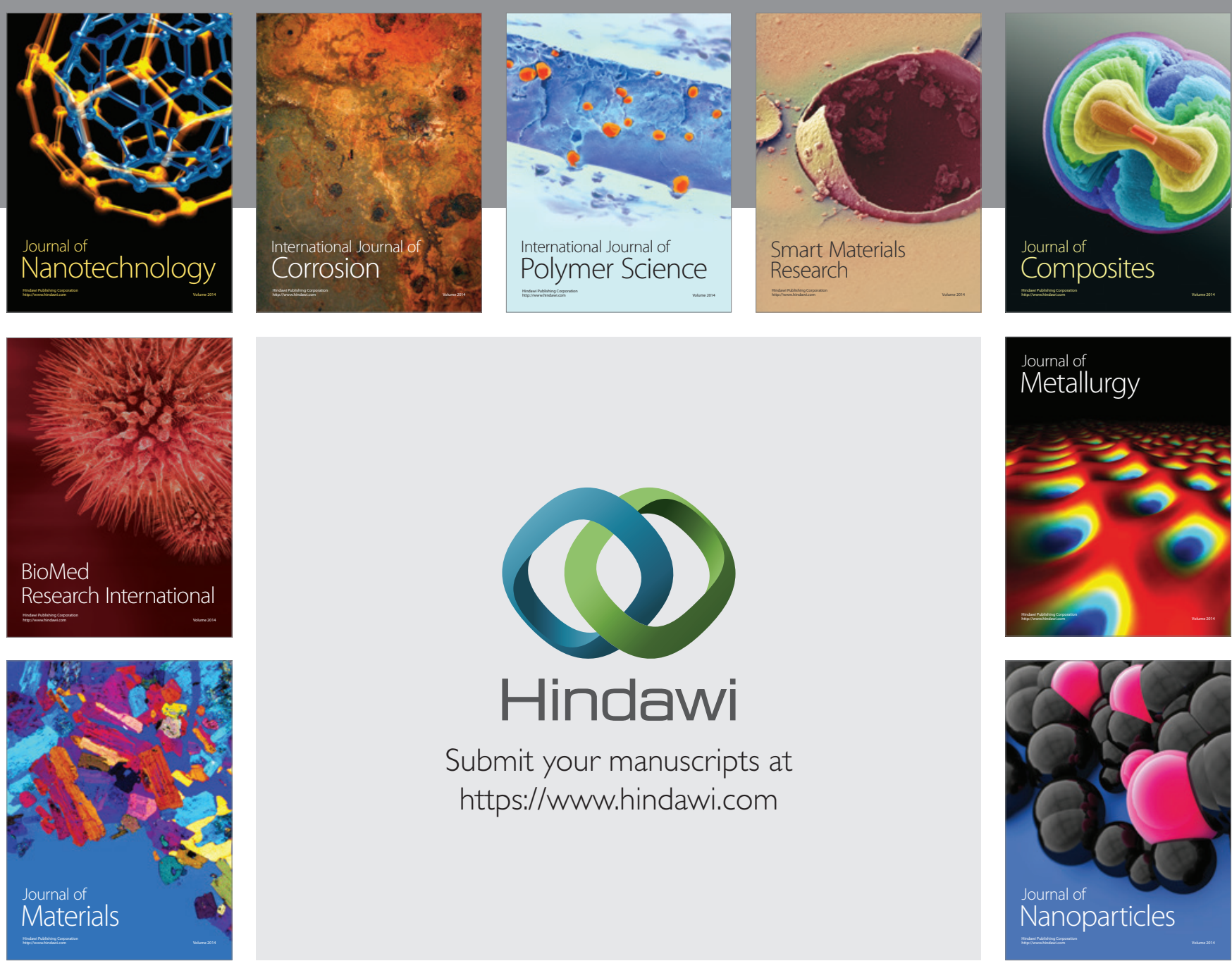

\section{Hindawi}

Submit your manuscripts at

https://www.hindawi.com

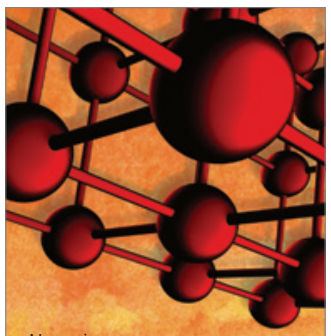

Materials Science and Engineering
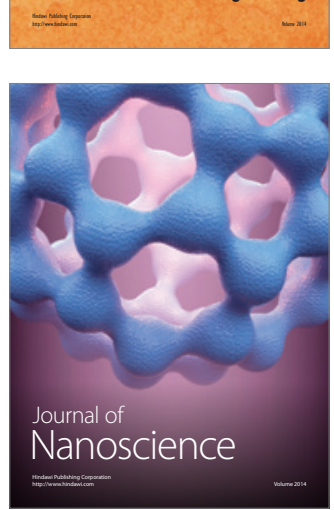
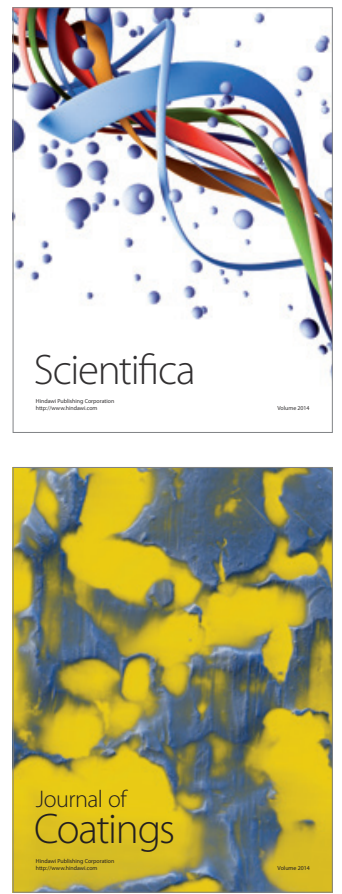
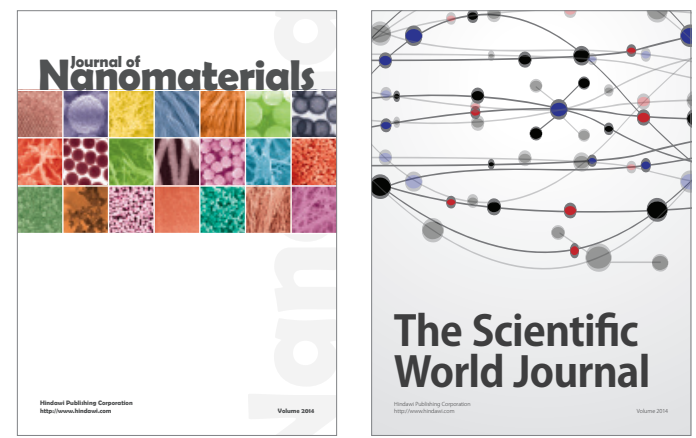

The Scientific World Journal
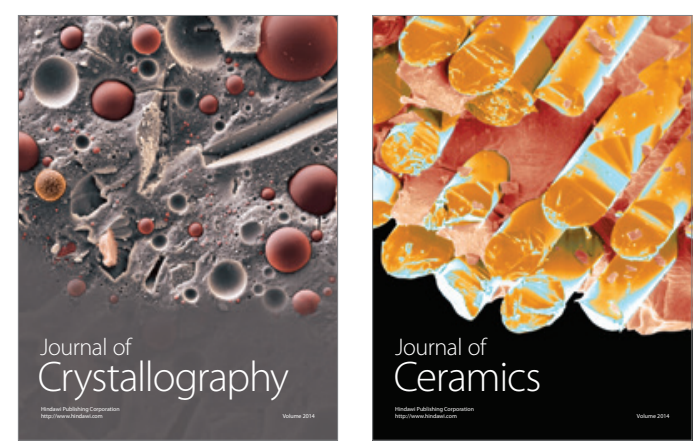
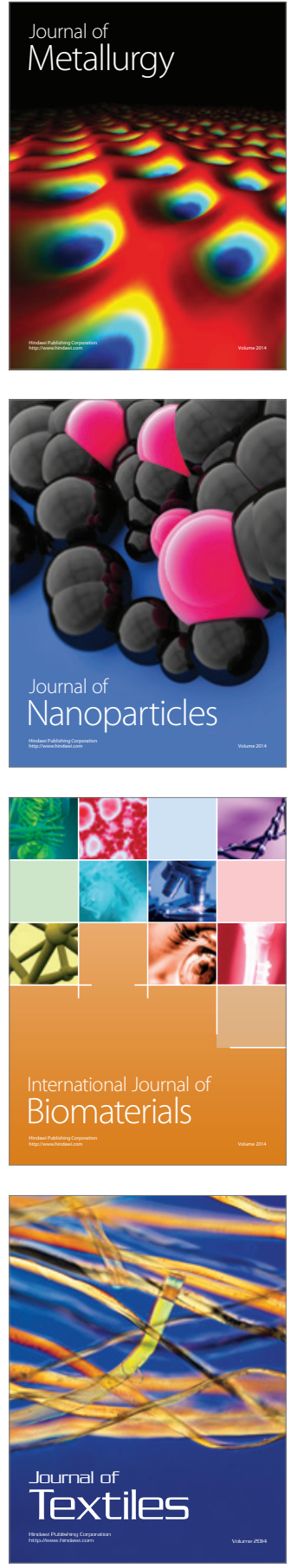